\title{
Health Utilities Index
}

National Cancer Institute

\section{Source}

National Cancer Institute. Health Utilities Index. NCI Thesaurus. Code C156124.

A family of generic health profiles and preference-based systems for measuring health status, reporting health-related quality of life, and producing utility scores. 